\title{
Unusual Presentation of Preauricular Sinus Abscess-Case Report
}

\author{
Benjamin N. Nkemjika1, Moses A. Akinola1, Chinonyerem Adiele1, Godswill I. Chiege² \\ ${ }^{1}$ Department of Otorhinolaryngology and Head and Neck Surgery, Babcock University Teaching Hospital, \\ Ilishan Remo, Ogun, Nigeria \\ ${ }^{2}$ ENT Unit, Nigeria Military Hospital, Ikoyi Lagos, Nigeria \\ Email: benzchusky2@gmail.com
}

How to cite this paper: Nkemjika, B.N., Akinola, M.A., Adiele, C. and Chiege, G.I. (2020) Unusual Presentation of Preauricular Sinus Abscess-Case Report. Case Reports in Clinical Medicine, 9, 53-58. https://doi.org/10.4236/crcm.2020.92009

Received: December 13, 2019

Accepted: February 3, 2020

Published: February 6, 2020

Copyright (c) 2020 by author(s) and Scientific Research Publishing Inc. This work is licensed under the Creative Commons Attribution International License (CC BY 4.0).

http://creativecommons.org/licenses/by/4.0/

\begin{abstract}
Preauricular sinus is a common congenital malformation. Unusual presentations can be subtle with some difficulty in obtaining diagnosis. A 27-year-old woman with 6 months history of recurrent right postauricular swelling which was initially thought to be a recurrent mastoid abscess presented. She had repeated incision and drainage with recurrent post auricular abscess. An incidental extravasation of fluid from an asymptomatic preauricular sinus during postauricular abscess cavity irrigation and a positive fistulogram revealed the diagnosis. Combined excision of the preauricular sinus tract and postauricular abscess cavity achieved a good outcome with patient been asymptomatic over a period of one-year follow-up. There should be a high index of suspicion of recurrent abscesses in close proximity with an ipsilateral preauricular sinus in the head and neck region.
\end{abstract}

\section{Keywords}

Preauricular Sinus, Postauricular Abscess, Fistulogram

\section{Introduction}

Preauricular sinus is a common congenital malformation characterised by a nodule, dent or dimple located anywhere adjacent to the external auditory canal [1]. They are not rare anomalies of the ear, though not frequently diagnosed in routine ear examinations. It was first described by Van Heusinger in 1864 [2]. It is formed from incomplete or abnormal fusion of the six auditory hillocks during embryological development of the auricle at the 6th week of intra-uterine life. It may either be unilateral or bilateral and can be hereditary or sporadic in distribution. The prevalence of preauricular sinus differs depending on the 
population ranging from $0.1 \%-0.9 \%$, in the USA; 0.9\%, in England and 4\% $10 \%$ in some parts of Africa. In Ilorin, North Central of Nigeria, a 9.3\% prevalence was noted [3].

Preauricular sinuses are susceptible to infections leading to preauricular sinus abscess. When it is infected results to erythema, discharge, oedema, pain and if the sinus ostium is blocked pus accumulates leading to abscess formation. It may also be complicated by infections spreading to contiguous structures such as pinna, external auditory canal and temporomandibular joint.

Differentials of postauricular abscess are inflamed adenopathy, infected epidermoid cyst, mastoiditis, subperiosteal abscesses, although the latter two cases mostly coexist with auditory and vestibular symptoms [4] [5].

This communication documents a preauricular sinus with unusual presentation while highlighting the features which culminated in its diagnosis and appropriate management.

\section{Case Report}

A 27-year-old lady presented to the Otorhinolaryngology (ORL) outpatient department with recurrent right postauricular swelling, discharge and an associated postauricular pain and headaches (Figure 1). A review of her past medical history revealed that she has had three episodes of similar right postauricular swelling and discharge in the past six months that was thought to be a mastoid abscess by a general practitioner and ENT/Head and Neck surgeon. A computed tomography (CT) scan of the temporomastoid region showed well pneumatized mastoid air cells bilaterally with an isodense lesion at the right postauricular region (Figure 2). She had three episodes of incision and drainage of a mastoid abscess but with recurrence of the right post aural swelling. At the last incision and drainage procedure, while irrigating the abscess cavity, extravasation of fluid through an asymptomatic ipsilateral preauricular sinus was noted which prompted a change in the diagnosis.

A fistulogram ordered showed a tiny tract measuring approximately $6.9 \mathrm{~mm}$ in thickness and $8.7 \mathrm{~cm}$ in length from the preauricular region and opening at the right post aural region (Figure 3 ).
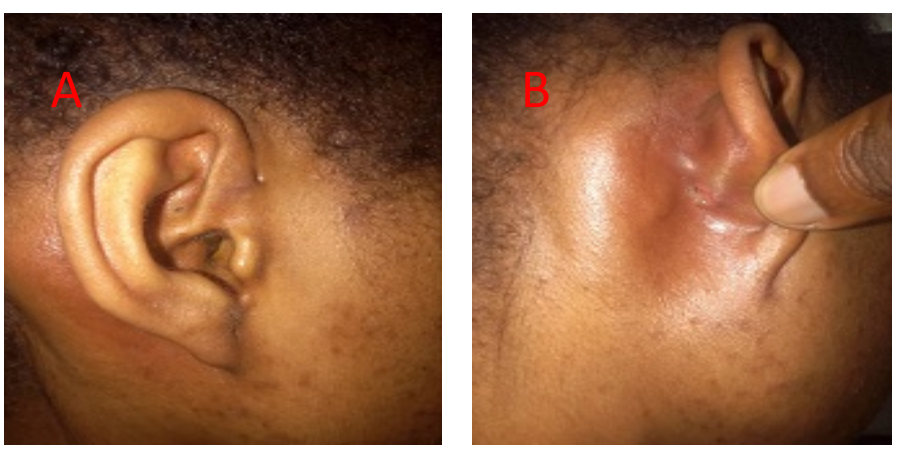

Figure 1. (A)-(B) Asymptomatic right preauricular sinus and post aural swelling with discharge in the patient. 


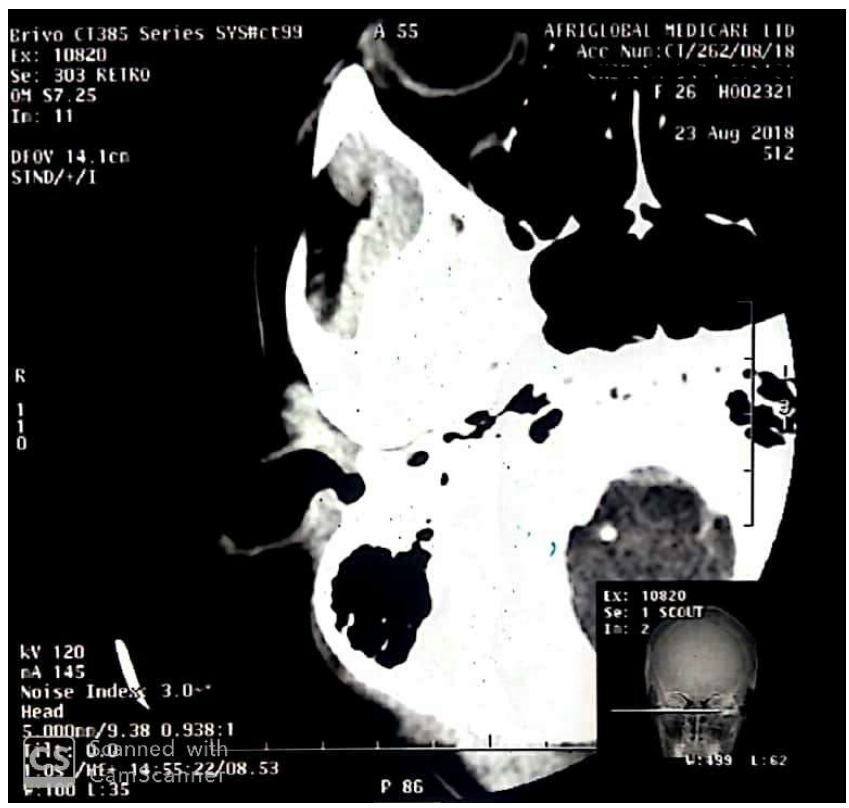

Figure 2. CT scan temporomastoid showing well pnuematized right mastoid air cells with subcutaneous isodensity at post aural region.

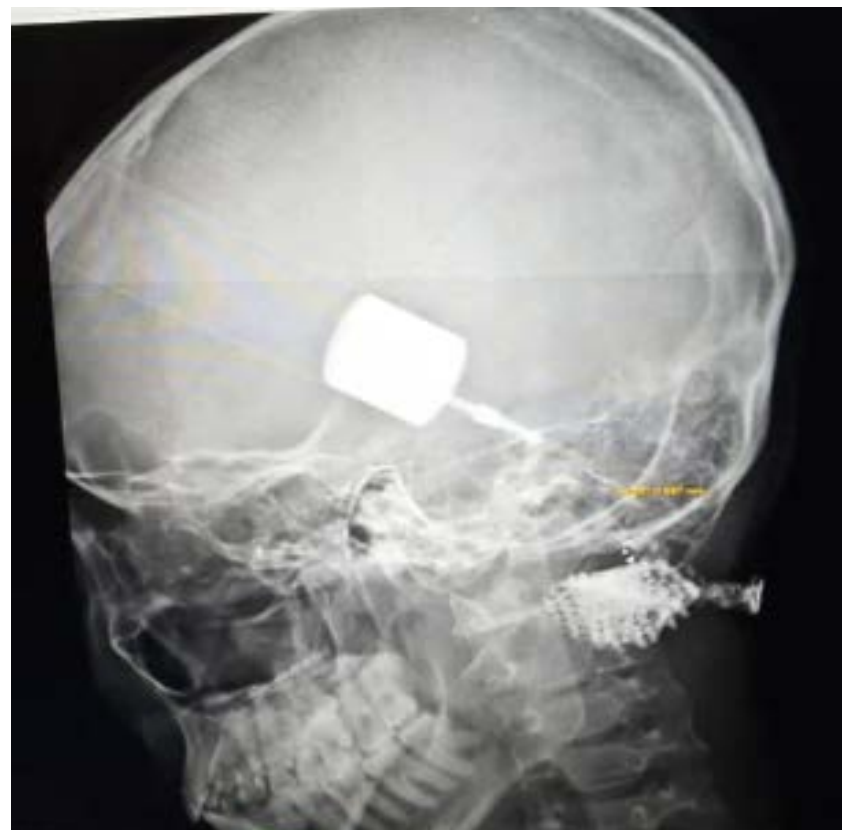

Figure 3. Fistulogram showing the course of the tract.

She was worked up for excision of right preauricular sinus complicated by a postauricular abscess. Intra-operatively an intraluminal staining via injection of methylene blue into the preauricular sinus was done and a combined excision of preauricular sinus tract and post auricular abscess cavity was done aided by use of surgical loupes. The finding at surgery was a tortuous tract running obliquely and posteriorly to the cymba concha, anti-helix and ending at the post aural region (Figure 4). 

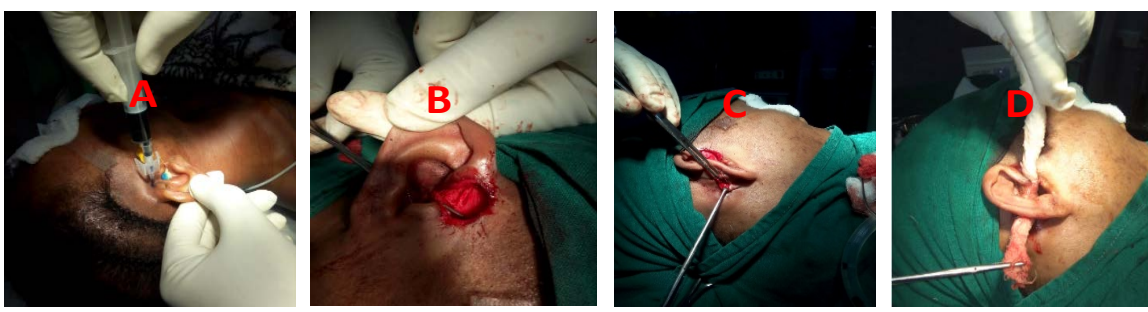

Figure 4. (A)-(D) Intraoperative photographs. From intraluminal injection of methylene blue into the sinus tract to a combined excision of preauricular and post aural abscess cavity while demonstrating the course of the excised fistula tract.

Post operatively patient was placed on antibiotics, analgesics and discharged the next day. She was reviewed in the outpatient clinic at 3 weeks, 6 months and 1 year post operatively with no signs of recurrence (Figure 5).

\section{Discussion}

There are several theories for development of preauricular sinus in literature. They include; a possible incomplete fusion of the first arch hillocks, isolation of ectodermal folds during auricle formation and defective closure of the most dorsal part of the first branchial cleft [6].

Preauricular sinuses can also mimic anomalies of the first branchial cleft. They usually present with an opening anterior to ascending limb of helix or an opening along the lateral or posterior surface of the helicine crus, superior posterior margin of the helix, tragus or the lobule [7].

The type 1 anomalies of first branchial cleft present as a sinus or cyst in the ear canal or post auricular region, whilst an opening in the cheek, below the angle of the mandible or upper neck above the hyoid bone suggest type II anomalies [8].

In the index case an asymptomatic preauricular sinus coexisted with a recurrent post auricular abscess swelling. There was no opening in the ear canal and the course of the tract was oblique to the ear canal, which strongly suggest a preauricular sinus abscess rather than a branchial cleft type I anomaly [5].

The absence of other ear symptoms indicating middle ear infections and the CT scan temporomastoid findings of well pneumatized mastoid air cells ruled out the mastoid abscess, while the incidental extravasation of fluid from the asymptomatic sinus during postauricular abscess cavity irrigation, increased isodensity of the subcutaneous tissue on the CT scan and the positive fistulogram suggested a preauricular sinus abscess. Spyropoulou et al reported a similar case in United Kingdom, of an unusual presentation of a preauricular sinus that had its only manifestation as recurrent postauricular abscesses in a 13-year-old boy [9]. Chang and $\mathrm{Wu}$ also reported three cases of preauricular sinus presenting as postauricular cyst [10].

The intraoperative use of methylene blue injection to delineate the fistula tract, use of surgical loupes for magnification and combined excision of preauricular sinus and post auricular abscess cavity ensured resolution of infection and recurrence. 

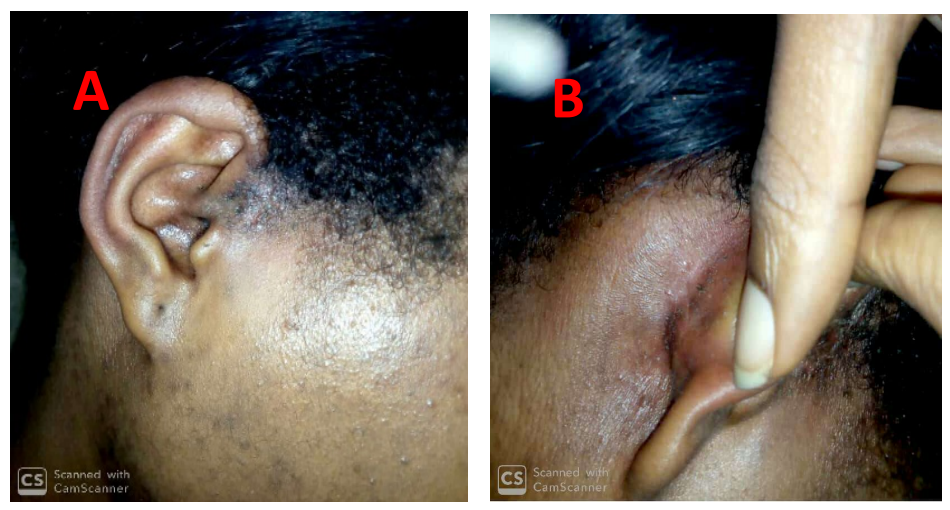

Figure 5. (A)-(B) 6 months post operatively, with good healing at both pre and post aural site.

\section{Conclusion}

There should be a high index of suspicion among clinicians of recurrent abscesses in close proximity with ipsilateral preauricular sinus in the head and neck region. Complete excision of the fistulous tract as was done in this case is necessary for its complete resolution.

\section{Conflicts of Interest}

The authors declare no conflicts of interest regarding the publication of this paper.

\section{References}

[1] Scheinfeld, N.S., Silverberg, N.B., Weinberg, J.M. and Nozad, V. (2004) The Preauricular Sinus: A Review of Its Clinical Presentation, Treatment, and Associations. Pediatric Dermatology, 21, 191-196.

https://doi.org/10.1111/j.0736-8046.2004.21301.x

[2] Heusinger, H.K. (1864) Hals-Kiemen Finstein von Noch Nicht Beobacheter Form. Archiv für pathologische Anatomie und Physiologie und für klinische Medicin, 29, 358-380. https://doi.org/10.1007/BF01937182

[3] Adegbiji, W.A., Alabi, B.S., Olajuyin, O.A. and Nwawolo, C.C. (2013) Presentation of Preauricular Sinus and Preauricular Sinus Abscess in Southwest Nigeria. International Journal of Biomedical Science, 9, 260-263.

[4] Chang, P.H. and Wu, C.M. (2005) An Insidious Preauricular Sinus Presenting as an Infected Postauricular Cyst. International Journal of Clinical Practice, 59, 370-372. https://doi.org/10.1111/j.1742-1241.2005.00437.x

[5] Choi, S.J., Choung, Y.H., Park, K., Bae, J. and Park, H.Y. (2007) The Variant Type of Preauricular Sinus: Postauricular Sinus. Laryngoscope, 117, 1798-1802. https://doi.org/10.1097/MLG.0b013e3180caa1ca

[6] Emery, P.J. and Salama, N.Y. (1981) Congenital Preauricular Sinus. A Study of 31 Cases Seen over a Ten-Year Period. International Journal of Pediatric Otorhinolaryngology, 3, 205-212. https://doi.org/10.1016/0165-5876(81)90004-5

[7] Yeo, S.W., Jun, B.C., Park, S.N., Lee, J.H., Song, C.E., Chang, K.H., et al. (2006) The Preauricular Sinus: Factors Contributing to Recurrence after Surgery. American Journal of Otolaryngology-Head and Neck Medicine and Surgery, 27, 396-400. 
https://doi.org/10.1016/j.amjoto.2006.03.008

[8] Nofsinger, Y.C., Tom, L.W., LaRossa, D., Wetmore, R.F. and Handler, S.D. (1997) Periauricular Cysts and Sinuses. Laryngoscope, 107, 883-887.

https://doi.org/10.1097/00005537-199707000-00009

[9] Alexandra Spyropoulou, G., Dionyssopoulos, A., Oikonomou, D. and Sterne, G. (2012) Uncommon Presentation of a Preauricular Sinus. Modern Plastic Surgery, 2, 61-63. https://doi.org/10.4236/mps.2012.23016

[10] Chang, P.H. and Wu, C.M. (2005) An Insidious Preauricular Sinus Presenting as an Infected Postauricular Cyst. International Journal of Clinical Practice, 59, 370-372. https://doi.org/10.1111/j.1742-1241.2005.00437.x 